Review

\title{
Review of phosphocholine substituents on bacterial pathogen glycans: Synthesis, structures and interactions with host proteins
}

\author{
N. Martin Young ${ }^{\mathrm{a}}$, Simon J. Foote ${ }^{\mathrm{a}}$, Warren W. Wakarchuk ${ }^{\mathrm{b}, *}$ \\ ${ }^{a}$ Human Health Therapeutics, National Research Council of Canada, 100 Sussex Drive, Ottawa, Ontario, Canada K1A OR6 \\ ${ }^{\mathrm{b}}$ Department of Chemistry and Biology, Ryerson University, 350 Victoria Street, Toronto, Ontario, Canada M5B 2K3
}

\section{A R T I C L E I N F O}

\section{Article history:}

Received 26 March 2013

Received in revised form 24 May 2013

Accepted 28 May 2013

Available online 1 August 2013

\section{Keywords:}

C-reactive protein

Haemophilus influenzae

Phosphocholine

Streptococcus pneumoniae

\begin{abstract}
A B S T R A C T
Among the non-carbohydrate components of glycans, the addition of phosphocholine (ChoP) to the glycans of pathogens occurs more rarely than acetylation or methylation, but it has far more potent biological consequences. These arise from ChoP's multiple interactions with host proteins, which are important at all stages of the infection process. These stages include initial adherence to cells, encountering the host's innate immune system and then the adaptive immune system. Thus, in the initial stages of an infection, ChoP groups are an asset to the pathogen, but they can turn into a disadvantage subsequently. In this review, we have focussed on structural aspects of these phenomena. We describe the biosynthesis of the ChoP modification, the structures of the pathogen glycans known to carry ChoP groups and the host proteins that recognize ChoP.
\end{abstract}

(c) 2013 The Authors. Published by Elsevier Ltd. Open access under CC BY-NC-ND license.

\section{Introduction}

The history of the investigation of ChoP-Ag interactions with host proteins dates back to the 1940s when Avery and colleagues (Abernathy and Avery, 1941; MacLeod and Avery, 1941a,b) described the reaction of C-substance from Streptococcus pneumoniae $(\mathrm{PnC})$ with an acute phase protein from serum, which they termed C-reactive protein (CRP). These reports provided a molecular basis for the earlier serological observations of Tillett and Francis (1930). Thirty years later, it was found that this interaction was mediated by ChoP groups on the PnC (Volanakis and Kaplan, 1971; Leon and Young, 1971). A pathway and corresponding gene locus for ChoP modification was first described in Haemophilus influenzae by Weiser et al. (1997), and homologs of the four genes in the lic1 locus were found in S. pneumoniae (Zhang et al., 1999). These two bacteria, one being gram-negative and the other gram-positive, have continued to be the major ones for the investigation of the properties of ChoP-modified glycans.

Abbreviations: ChoP, choline phosphate; PnC, pneumococcal C substance; CRP, $C$ reactive protein; PAF, platelet-activating factor; LTA, lipotechoic acid; TAA, 2acetamido-4-amino-2,4,6-trideoxyhexose; ZPS, zwitterionic polysaccharide.

* Corresponding author. Tel.: +1 416979 5000x3207; fax: +1 4169795044.

E-mail addresses: martin.young@nrc-cnrc.gc.ca (N.M. Young), wwakarchuk@ryerson.ca (W.W. Wakarchuk).
Despite the relative rarity of the ChoP modification, it is extraordinarily diverse, occurring on all of the major classes of bacterial polysaccharides and attached to different hydroxyls on a variety of hexoses. As will be summarized here, ChoP-modified glycans can interact with several different host proteins, which can aid cellular uptake but also renders the bacteria susceptible to attack from proteins of both the innate and adaptive immune systems. It therefore has a far more significant effect on polysaccharide properties than the more common modifications of acetylation or methylation, which only modulate antigenic structure. For a more complete description of the microbiology of the ChoP modification, see the recent review by Clark and Weiser (2013). While ChoP is the focus of this review, it should be noted that glycans modified with the related compound phosphoethanolamine will share some of the properties of ChoP-modified glycans.

\section{Biosynthesis of the ChoP modification}

ChoP groups are synthesized and added to glycans by the actions of proteins from lic gene clusters. In $H$. influenzae, the genes are subject to phase variation, leading to gain or loss of the ChoP modification, which then modulates the interactions of the bacteria with host proteins. The overall biosynthetic process is summarized in Fig. 1.

\subsection{Obtaining choline}

Bacteria do not synthesize choline themselves but acquire it from the host, aided by phosphodiesterases such as the $H$. 

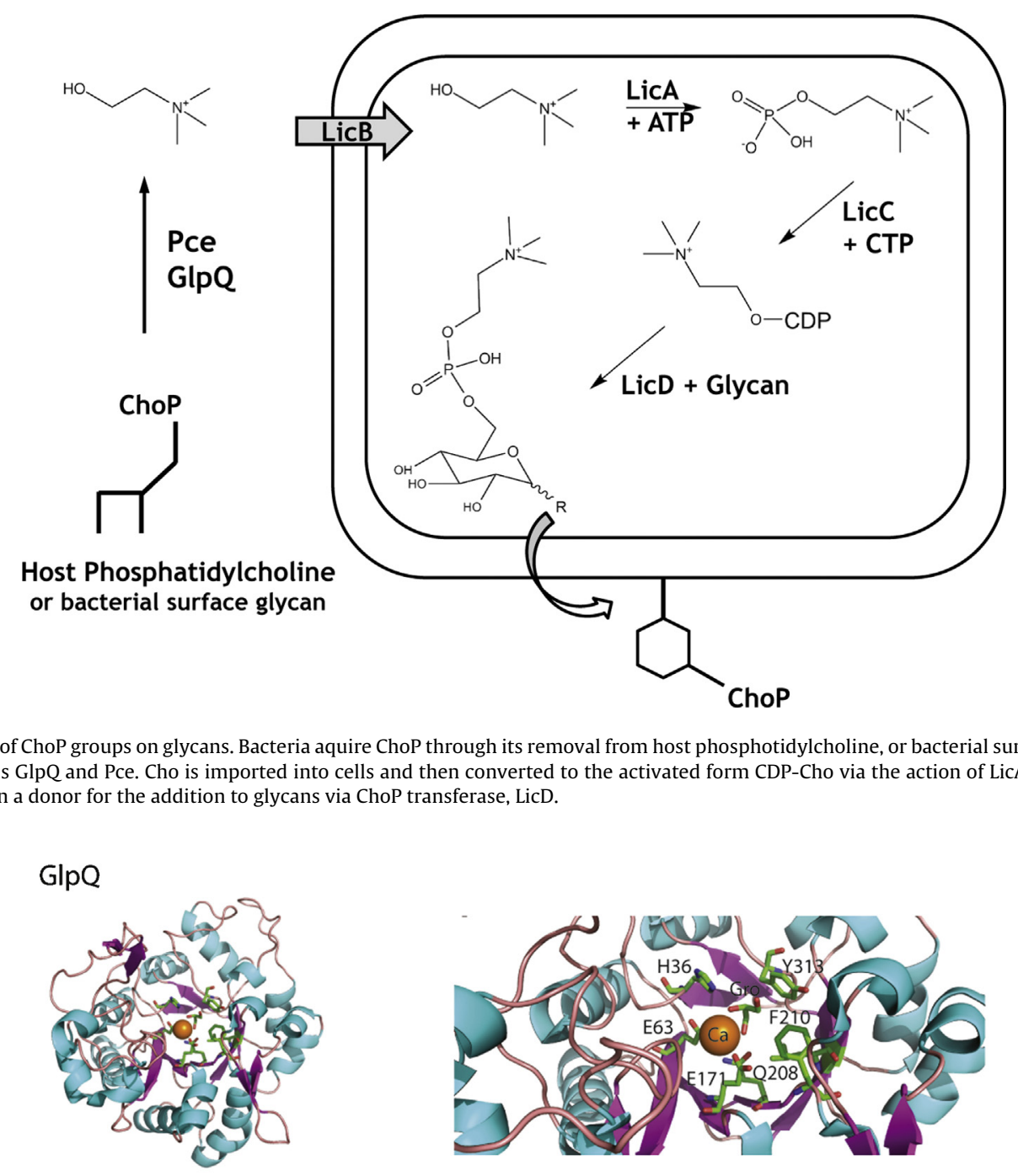

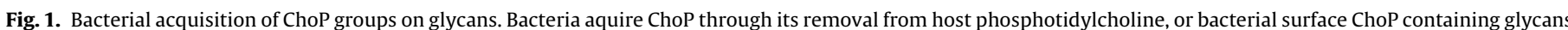

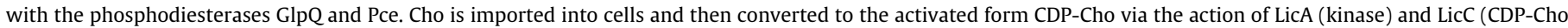
synthetase). CDP-Cho is then a donor for the addition to glycans via ChoP transferase, LicD.
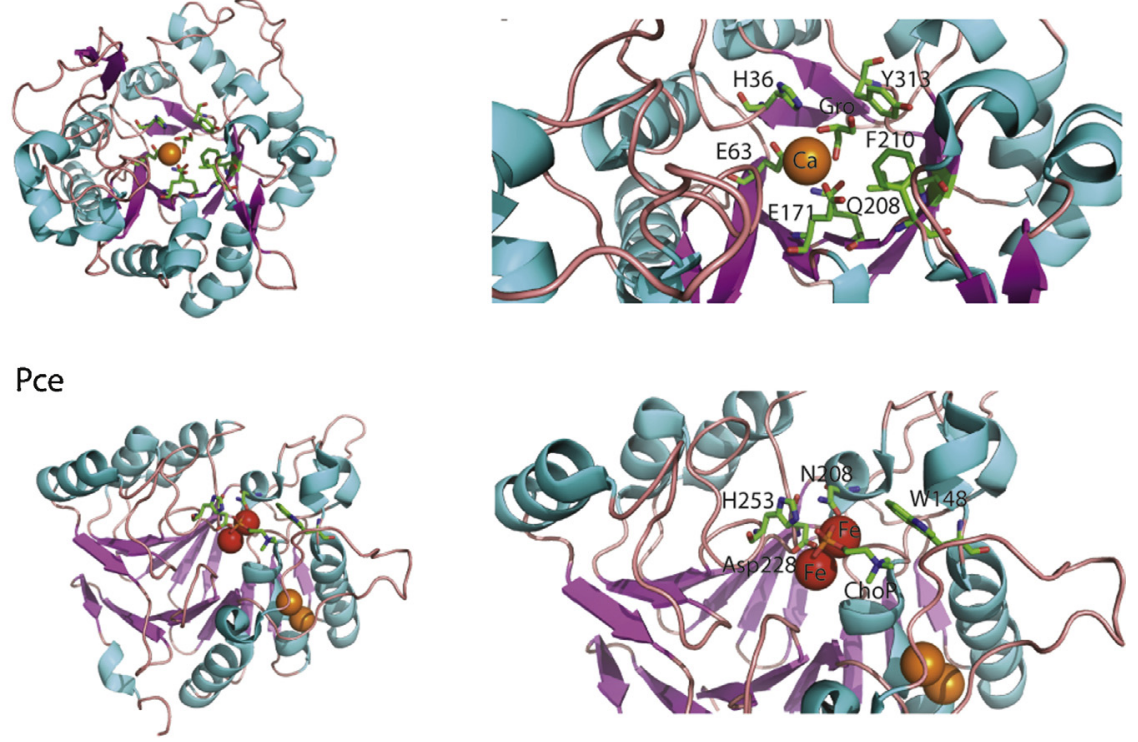

LicC
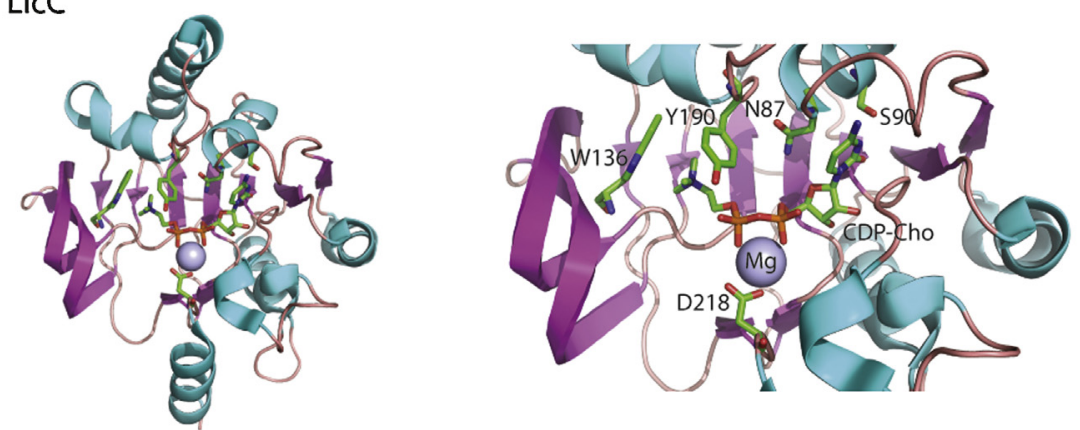

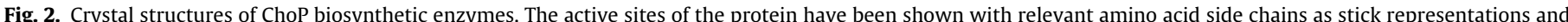

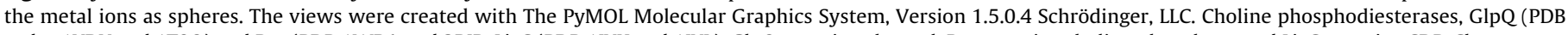
codes 1YDY and 1T8Q) and Pce (PDB 1WRA and 2BIB, LicC (PDB 1JYK and 1JYL). GlpQ contains glycerol, Pce contains choline phosphate, and LicC contains CDP-Cho. 

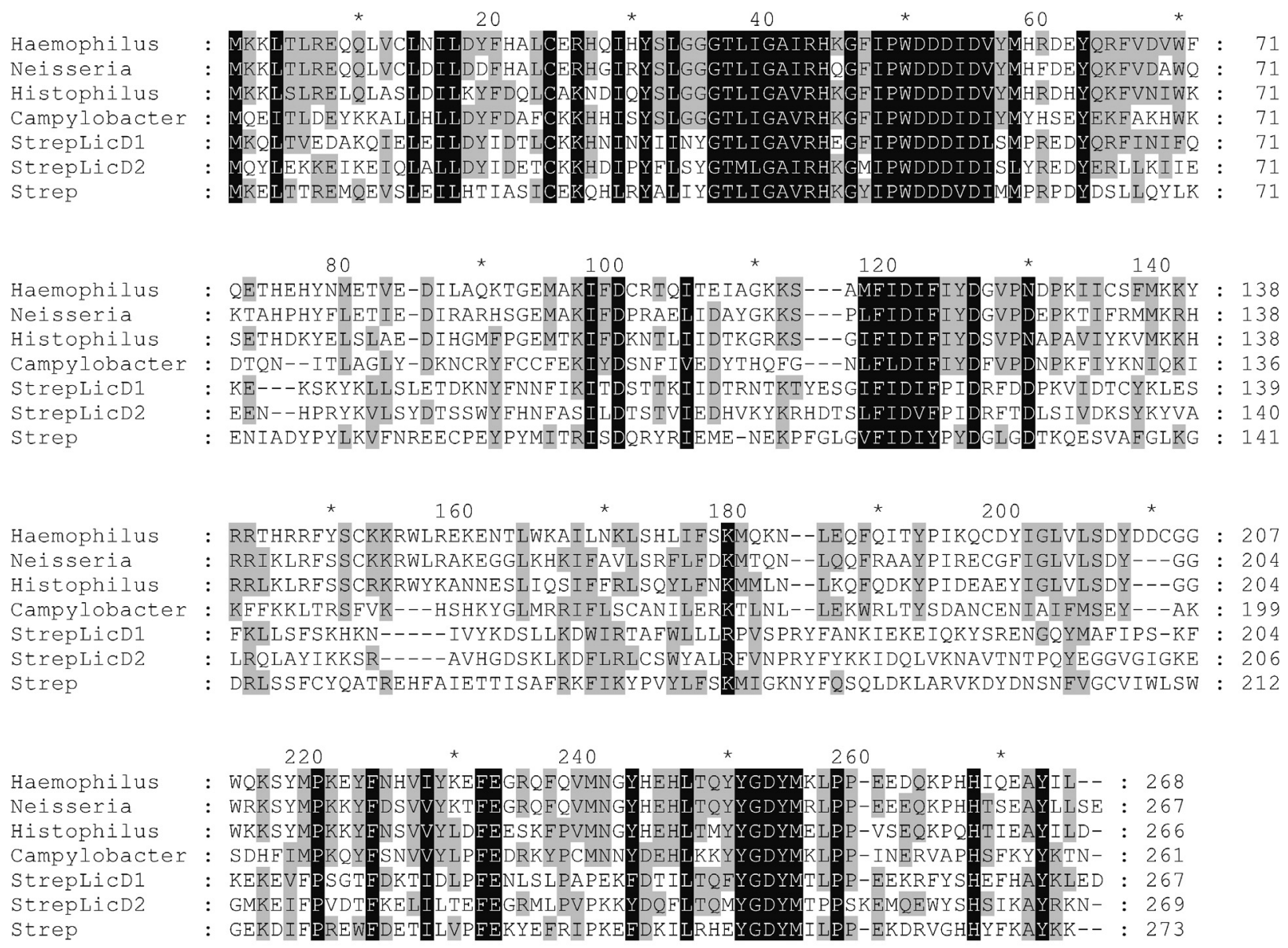

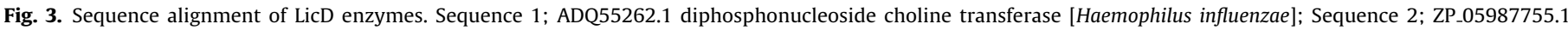

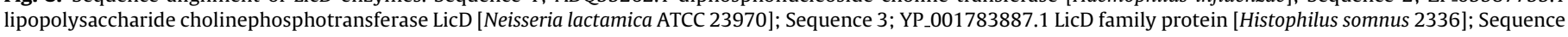

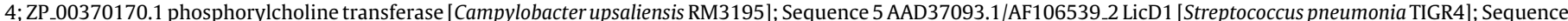

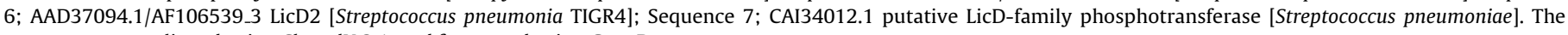
sequences were aligned using ClustalX 2.1, and formatted using GeneDoc.

influenzae GlpQ enzyme which can release choline from host lipids (Fan et al., 2001), greatly supplementing the free choline levels in adult sera or saliva of $\sim 10 \mu \mathrm{M}$ (Human Metabolome Database, http://www.hmdb.ca). GlpQ is highly homologous to the Escherichia coli enzyme whose structure has been deposited in the Protein Databank by two Structural Genomics Centers (PDB codes $1 Y D Y$ and $1 T 8 Q$ ). It is an $\alpha / \beta$ barrel structure, with a requirement for $\mathrm{Ca}^{2+}$ in the active site (Fig. 2), and it is capable of hydrolysing a variety of deacylation products of glycerophospholipids. The E. coli enzyme is a periplasmic one, but the $H$. influenzae homolog was recognized as a surface lipoprotein, Protein D, before its activity was discovered (Munson and Sasaki, 1993). Because its sequence is relatively invariant, it has been utilized as a vaccine directly or as the protein component of a conjugate vaccine (Forsgren et al., 2008).

In $S$. pneumoniae, the esterase Pce is one of a family of $S$. pneumoniae proteins with choline-binding domains which anchor them to the bacterial cell surface. The crystal structures of the esterase domain (Garau et al., 2005; PDB code 1WRA) and of the whole protein (Hermoso et al., 2005; PDB code 2BIB) have been determined. It is also an $\alpha / \beta$ barrel protein like GlpQ (Fig. 2), but belongs to a different protein family, the $\beta$-lactamase superfamily. Its active site is more complex than that of GlpQ and includes two essential metal atoms which were reported as zinc by Hermoso et al. (2005) while Garau et al. (2005) determined they were both iron atoms; a direct interaction with one $\mathrm{Fe}^{3+}$ atom was seen in its complex with phosphocholine (Fig. 2). In addition to providing choline for the bacterium from host lipids, Pce may also alter the interactions of $S$. pneumoniae with ChoP-binding proteins of the host, by removing ChoP from its teichoic acids (Vollmer and Tomasz, 2001). It has been hypothesized that a reduction in the levels of surface ChoP could reduce interaction of the cell with the oligomeric innate immunity factor, CRP, without affecting the monomeric interaction with the receptor for platelet-activating factor (PAF). This factor is a small soluble lipid molecule, 1-O-alkyl2-acetyl-sn-glycero-3-phosphocholine, with multiple roles beyond platelets, and its receptor provides an important route for cellular adhesion and invasion by pathogens. Pce may also aid invasion by destroying PAF. Thus the surface levels of ChoP can be modulated in entirely different ways in bacteria, i.e., by phase variation in $H$. influenzae and by phosphodiesterase action in S. pneumoniae.

\subsection{Synthesis of CDP-choline}

The biosynthetic roles of the proteins made by the four lic1 genes of $H$. influenzae (Fig. 1) were initially assigned from their homology to proteins of known function (Weiser et al., 1997), and have been confirmed biochemically for three of them. The naming of these genes/proteins originally used the more cumbersome names like lic1A/Lic1A, but we have dropped the number and use only the letter designation as a simplification. The first two proteins from the locus are assigned as a choline kinase, LicA, and a choline 
transmembrane transporter, LicB (based on homology only). The LicA gene product in $H$. sommus has been shown to convert free choline to ChoP (Elswaifi et al., 2009). LicC is the best characterized protein in the pathway and it synthesizes CDP-choline from ChoP and CTP, in the cytoplasm. The crystal structure of the S. pneumoniae enzyme (Fig. 2) placed it in the NTP transferase superfamily and explained many features of the enzyme's mechanism, including its requirement for $\mathrm{Mg}^{2+}$ (Kwak et al., 2002; PDB codes 1JYK and 1JYL).

The lic locus in $S$. pneumoniae contains eight genes, including LicA, LicB, LicC and two LicD homologs (Zhang et al., 1999). Functions for the other three genes have been proposed (see below) (Denapaite et al., 2012).

\subsection{Attachment of ChoP to glycans}

The final enzyme, LicD, is a ChoP transferase which adds ChoP to the target glycans. In S. pneumoniae, there are two forms of this enzyme, produced from contiguous genes. Since their teichoic acid substrate, PnC, contains two ChoP groups, the LicD1 and LicD2 enzymes may each modify a specific GalNAc in the glycan's structure (see below), but this has yet to be proved. However a licD2 knockout produced a form of PnC with less ChoP, and the physical and invasive properties of the bacterium were significantly altered (Zhang et al., 1999).

Sequence alignment of the S. pneumoniae and H. influenzae LicD enzymes shows they are $38 \%$ identical (Fig. 3). Perhaps surprisingly, the homology of the S. pneumoniae PnC LicD enzymes to those that modify certain of the type-specific capsular polysaccharides was similar, 35\% identity, suggesting the latter's licD genes were not acquired from the PnC locus. BlastP searches of other genomes in Genbank with the $H$. influenzae LicD have identified several other candidate organisms for ChoP-containing glycans, including Campylobacter upsaliensis (Fouts et al., 2005), but there are no chemical data to confirm they have ChoP groups on their glycans.

\section{PC-glycan structures}

The Bacterial Carbohydrate Structure Database (http://csdb. glycoscience.ru/bacterial/) contains 134 entries for cholinecontaining polysaccharides. However there is a high degree of redundancy among these entries, particularly for $H$. influenzae structures. The list can be reduced to the major structures listed in Table 1, which omits ones formed by phase variation. ChoP groups have been found on all the different types of bacterial glycans, and can be attached to the $\mathrm{O} 2, \mathrm{O} 3, \mathrm{O} 4$ or $\mathrm{O} 6$ positions of a variety of hexoses, as well as $\mathrm{O} 7$ of a heptose.

By means of the Database for prOkaryotic OpeRons or DOOR (Mao et al., 2009) a search was made of the many available bacterial genome sequences for other examples of lic loci, which would indicate ChoP-glycans in other bacteria. Only Clostridium species showed any hits, but these were restricted to licA and licB gene pairs. Hence, if further examples of ChoP-modified glycans exist in any of the sequenced bacteria, they must be synthesized by non-contiguous lic genes. BLASTp searches were therefore made with LicD sequences from S. pneumoniae PnC (LicD1) and type 27, and $H$. influenzae. These identified several other species of bacteria with highly homologous proteins. The type 27 homologs with 93-58\% sequence identity included S. anginosus and oral sp., Roseburia inulinivirans, Butyrivibrio crossatus and Actinobacillus minor (a Clostridium gene was $47 \%$ identical). PnC LicD1, which has only $35 \%$ sequence identity to type $27 \mathrm{LicD}$, produced a quite different set of homologs, which included genes from S. mitis, S. pseudopneumoniae, S. peroris, Granella sanguinis, Graniculata elegans and Parvimonas micra; their sequence identities were from $97 \%$ to $56 \%$.
The H. influenzae LicD homologs were from $H$. haemolyticus, three Neisseria species: $N$. polysaccharea, $N$. flavescens and $N$. lactamica, and Histophilus sominus; their sequence identities were from $85 \%$ to $66 \%$.

\subsection{Teichoic acids}

In S. pneumoniae, two forms of teichoic acid occur, one attached to the cellwall peptidoglycan and the other to lipid (LTA). However, both bear the same polysaccharide structure (Fischer et al., 1993). The presence of choline on S. pneumoniae cell surfaces and specifically on its teichoic acid PnC was established many years ago, but the complete elucidation of the complex structure of this glycan was not possible until more sophisticated NMR tools were developed. The currently accepted structure of the polysaccharide from the strain R36 is shown in Table 1 (Kulakowska et al., 1993). The repeating unit contains two D-GalNAc residues, a D-Glc, a 2-acetamido-4-amino-2,4,6-trideoxyhexose (TAA) with a $\mathrm{D}-\mathrm{Gal}$ configuration, and a ribitol. The units are linked together by phosphodiester bonds from the ribitol, hence PnC is a member of the ribitol phosphate family of teichoic acids. Both of the GalNAc residues are substituted at $\mathrm{O} 6$ with $\mathrm{ChoP}$, though the overall content can vary (Karlsson et al., 1999). Variations in the structures of C-polysaccharides from different strains have also been found (Draing et al., 2006). As mentioned above, there are two ChoP transferases in the $S$. pneumoniae lic locus, so they may be specific for one or the other GalNAc. Surprisingly the sequence homology of LicD1 and LicD2 is only $45 \%$ identity. This value is comparable to the homology of LicD1 to the H. influenzae LicD, which is $38 \%$.

A complete analysis of the genetic pathway for $\mathrm{PnC}$ has recently been presented, which proposes functions for many genes beyond the lic locus (Denapaite et al., 2012). The biosynthesis begins with conversion of UDP-GlcNAc into the TAA sugar (Seo et al., 2008) followed by its transfer to a lipid carrier. The remaining elements of the repeating unit are sequentially built up on the TAA, polymerized to create the polysaccharide and the lipopolysaccharide is "flipped" across the membrane. Here it is either attached to the peptidoglycan of the cell wall or to another lipid to form the LTA. It is interesting to compare this route to the $N$-glycoprotein one in Campylobacter jejuni, which also begins with synthesis of a TAA from UDP-GlcNAc, followed by transfer to a lipid carrier, elongation to a heptasaccharide, flipping across the inner membrane into the periplasm and finally attachment to protein (Larkin and Imperiali, 2011). It is tempting to speculate that the synthesis of other oligosaccharide units that include a TAA may follow the same general pathway.

\subsection{Capsular polysaccharides}

By means of monoclonal antibodies specific for ChoP, six out of 83 different capsular types of $S$. pneumoniae were shown to have ChoP constitutents: types 24A, 27, 28F, 28A, 32F and 32A (Skov Sørensen et al., 1984). In addition, it has been found that types $15 \mathrm{~B}$ and $15 \mathrm{C}$ are partially substituted ( $\sim 20 \%)$ with ChoP (Jansson et al., 1987). The structures of only three of the six polysaccharides, types 32F and 32A (Karlsson et al., 1998), and type 27 (Bennett and Bishop, 1977) have been solved. The ChoP substituents in these types all occur in different positions from each other and from PnC (Table 1). The type $15 \mathrm{~s}$ has ChoP on $\mathrm{O} 3$ of $\mathrm{D}-\mathrm{Gal}$, the type $32 \mathrm{~s}$ on $\mathrm{O} 3 \mathrm{of} \mathrm{L}-$ Rha and the type 27 on 02 of L-Rha. Only type 15B is included in the current 23-valent anti-pneumococcal vaccine Pneumovax, and none of these types are in the 13-valent conjugate vaccine Prevnar. While there may be traces of PnC in them as well, ChoP does not therefore appear to be a significant epitope in these vaccines.

The polysaccharide loci from $90 \mathrm{~S}$. pneumoniae strains have been sequenced (Bentley et al., 2006), but a search of them for LicD 
Table 1

Structures of ChoP-modified glycans.

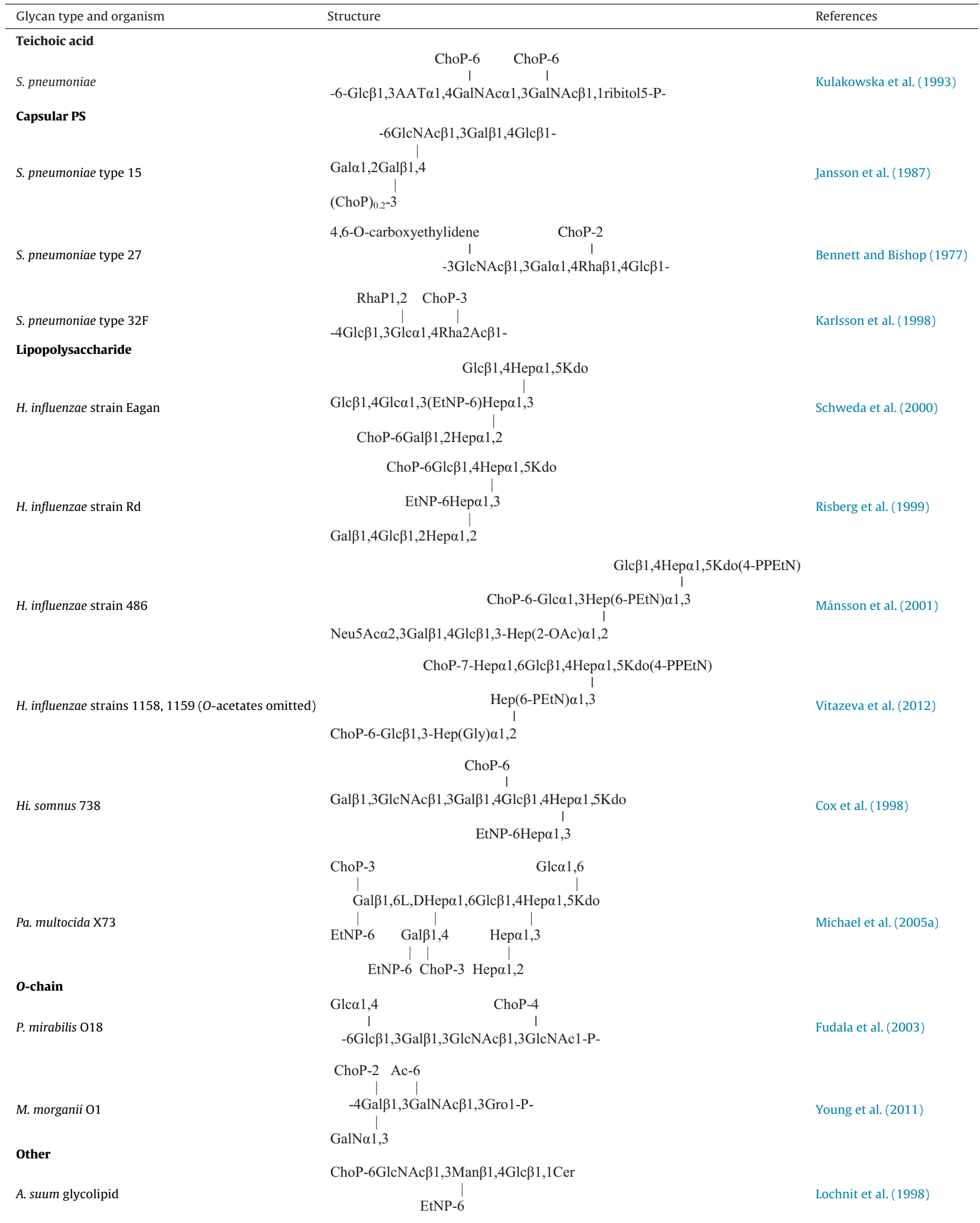


genes that would indicate further examples of ChoP modifications was negated by the fact that ribitol phosphate transferases are also LicD paralogs, and there are multiple examples of ribitol phosphate groups in these polysaccharides. Notably, there are licD genes in the loci of types $27,32 \mathrm{~A}$ and $32 \mathrm{~F}$ but not in the loci of types $24 \mathrm{~A}$, $28 \mathrm{~A}$ or $28 \mathrm{~F}$. This suggests that either the serological tests of Skov Sørensen et al. (1984) were picking up contamination by PnC or that their LicD enzymes come from genes outside the locus. The type 15 strains also lack licD genes in their loci, hence it is possible that the low level of ChoP found in these polysaccharides (Jansson et al., 1987) is a side reaction of the PnC LicD.

\subsection{Lipopolysaccharides}

Much of the recent interest in ChoP modifications has come from investigations by Weiser and associates of the short-chain LPS (or lipooligosaccharides) of nontypeable strains of $H$. influenzae, and the influences of ChoP groups on their biological properties. The expression of $\mathrm{ChoP}$ is intimately related to pathogenesis. It not only aids adherence through the PAF receptor (Swords et al., 2000) but also contributes to biofilm formation (Hong et al., 2007a,b), and thus to persistence in the respiratory tract (Weiser et al., 1998; Weiser et al., 2007).

These LPS structures are completely different from the above S. pneumoniae polysaccharides and consist of short glycan chains branching off a conserved structure consisting of a tri-heptosyl unit with Glc and phosphoethanolamine groups, which is attached to a Kdo residue and Lipid A of the inner core (Table 1). Many variant forms of these LPS structures have been analyzed, chiefly by Schweda and colleagues, and those shown in Table 1 are representative ones only. For more examples of these complex structures, see Schweda et al. (2007); this review also includes the assignments of the various glycosyltransferase genes that create the LPSs. Molecular mimicry of host glycan structures by the branches off the LPS can occur; examples include a globoside structure in nontypeable strain 1124 (Yildirim et al., 2005) and sialylLacNAc in strain R2846 (Lundström et al., 2008). The structural variations among the LPS species arise not only from the gene contents of each strain but also from phase variation in the expression of key glycosyltransferases that make the various branches, and of ChoP biosynthetic enzymes (Swords et al., 2003; Schweda et al., 2007).

The LPS carry ChoP at different sites, depending on the strain (Table 1 ), and this has been correlated with variations in the LicD genes (Lysenko et al., 2000). The sites are the 06 positions of D-Gal or D-Glc on the HepI (i.e., the Hep proximal to the Kdo residue) or HepIII arms of the Eagan or Rd strains, which are more accessible positions than those in the S. pneumoniae CPS. Additionally, nontypeable strain 486 has ChoP on the $\mathrm{O} 6$ of a Glc attached to the HepII (Månsson et al., 2001). The positional differences also lead to the strains showing different biological properties, notably susceptibility to CRP-mediated bacteriocidal action (Lysenko et al., 2000). The lic1A gene includes tandem repeats of 5'-CAAT-3', which leads to phase-variable expression of the ChoP constituents (Weiser et al., 1997). In some strains, e.g., isolate 1158 , there are duplicate copies of the lic1 locus which leads to the addition of two ChoP groups, on the HepI and HepIII arms respectively (Fox et al., 2008). The two ChoP residues have recently been located on this LOS (Table 1), one of them being a novel example of substitution at 07 of a heptose (Vitazeva et al., 2012).

Histophilus (Haemophilus) somnus (Cox et al., 1998) and two Pasteurella multocida strains (Michael et al., 2005a,b) also have short-chain LPS with ChoP groups, attached at the 6 position of Glc and the 3 position of Gal respectively (Table 1 ). The ChoP content is subject to phase variation (Howard et al., 2000). Neisseria species have been reported to carry ChoP on their LOS, and to have lic-related genes (Serino and Virij, 2000, 2002). C. upsaliensis also has a lic locus (Fouts et al., 2005), but structures have not yet been reported for these Neisseria and Campylobacter LPS species.

\subsection{O-Chains}

Proteus mirabilis $\mathrm{O} 18$ contains the first example found of a ChoPmodified $O$-chain repeat (Fudala et al., 2003); the ChoP is on the $\mathrm{O} 4$ position of a GlcNAc (Table 1). A second example occurs in Morganella (Proteus) morganii (Young et al., 2011) an organism which was first suspected to have a ChoP-glycan on the basis of tests with murine myeloma proteins specific for ChoP (Potter, 1971). This $O$-chain is also unusual in the number of charged groups it has (Table 1), which confer on it immunological properties associated with other zwitterionic polysaccharides (see below). The ChoP group is attached at the $\mathrm{O} 2$ position of a $\mathrm{D}-\mathrm{Gal}$. These two bacteria belong to the same group, the Proteaceae.

\subsection{Glycolipids and glycoproteins}

The occurrence of ChoP on the glycolipids, protein $N$-glycans and protein $O$-glycans of eukaryotic parasites, including nematodes and protozoa, and its immunological consequences have recently been comprehensively reviewed in this journal by Grabitzki and Lochnit (2009); hence they will not be described in depth here. As an example, Ascaris suum glycosphingolipids carry ChoP on 06 of terminal or internal GlcNAc residues (Lochnit et al., 1998), and the same structures occur in Caenorhabditis elegans among others. The sites of ChoP attachment to the $\mathrm{N}$ - and $\mathrm{O}$-glycans of glycoproteins have not been reported. In contrast to the bacterial route described above, the parasites have multiple complex metabolic routes to their ChoP glycolipids, and are not dependent on choline obtained from the host. The nematode ChoP glycans can down-regulate the cellular immune responses of the host, aiding the long-term persistence of the parasites.

ChoP can also be attached directly to proteins, and three striking examples of this are worth noting. Neisseria pili carry $\mathrm{O}$ linked ChoP and phosphoethanolamine on their subunits (Naessan et al., 2008), which are attached by an enzyme related to the LPS phosphoethanolamine transferases. The ChoP modification is phase-variable (Weiser et al., 1998). The modified pili could support interactions with host proteins similar to those of the above ChoP-modifed glycans. Indeed, it has recently been found that ChoP-modified pili on

Acinetobacter baumannii allow it to interact with PAF receptors on human lung epithelial cells (Smani et al., 2012). In a phenomenon of a totally different nature, Legionella pneumophila has recently been found to add ChoP to an intracellular host protein, the small GTPase Rab1, thus modifying its activity as part of the bacterium's invasive strategy (Tan et al., 2011).

\section{Interactions with host proteins}

ChoP-bearing bacteria successively encounter several types of host proteins capable of recognizing ChoP, starting with a target for adhesion, the cell-surface PAF receptor, followed by components of the innate immune system, $\mathrm{C}$-reactive protein and Toll-like receptors, and finally two parts of the adaptive immune system, MHCII protein and antibodies. These proteins recognize ChoP groups by means of completely different types of site, and in some cases the interactions are not the conventional ones for the proteins.

\subsection{Platelet-activating factor receptor}

PAF was originally identified as a leukocyte derived mediator through its effects on platelets, including histamine release, but it 
is now known to have a wide range of physiological roles including inflammatory and thrombotic responses (Yost et al., 2010). The effects of PAF on cells are mediated by a specific receptor, which is a member of a subset of the G-protein-coupled receptor family that includes rhodopsin. Models of it have therefore been constructed based on its homology to rhodopsin (Kajihara et al., 1994). The ChoP part of PAF is critical to its receptor recognition. The receptor was found to be a major adherence factor for S. pneumoniae (Cundell et al., 1995) and for H. influenzae (Swords et al., 2000), which interact with the PAF receptor on cells of the nasopharynx through the bacterial glycans' ChoP moieties. Thus, compounds which inhibit the interaction of PAF with the receptor can also block bacterial adherence (Cundell et al., 1996). It has been proposed that other nasopharyngeal bacteria share this ChoP route, e.g., Neisseria.

\subsection{C-reactive protein}

CRP is a member of the pentraxin family (i.e., a pentameric lectin) which recognizes both ChoP and phosphoethanolamine in a $\mathrm{Ca}^{2+}$ dependent manner (reviewed by Black et al., 2004). A second human pentraxin, serum amyloid $P$ component (SAP) also recognizes phosphoethanolamine and with a higher affinity (Mikolajek et al., 2010), but it does not bind ChoP. CRP homologs are present in many animals, even in invertebrates such as the horseshoe crab, Limulus polyphemus (Robey and Liu, 1981). It is an acute phase protein in humans, i.e., its serum level is greatly increased in inflammation. CRP is a key component of the innate immune system, and its binding to bacterial ChoP-glycans leads to complement activation, causing cytotoxicity. Hence it was protective against pneumococcal infections in mouse models (Szalai et al., 1995) and sensitized $H$. influenzae to serum killing (Weiser et al., 1998). Its structure has been determined crystallographically (Shrive et al., 1996; PDB code 1GNH; Mikolajek et al., 2010; PDB code 3L2Y) and the ChoP binding site is located on the central surface of one of its two $\beta$-sheets. Thus the five sites are all on the same face of the pentamer (Fig. 4) and are well placed for multivalent interactions with ChoP groups arrayed on a glycan. It has recently been shown that the integrity of the ChoP binding site is essential for protection against pneumococcal infection (Gang et al., 2013). The affinity of human CRP for ChoP determined by isothermal calorimetry is $5 \times 10^{5} \mathrm{M}^{-1}$ (Mikolajek et al., 2010), which is similar to the value determined for rabbit CRP (Bach et al., 1977); the affinity of human CRP for glycerophosphorylcholine was $1.4 \times 10^{5} \mathrm{M}^{-1}$ (Young and Williams, 1978). The latter molecule resembles the ChoP structures on polysaccharides, so its affinity is a better reflection of CRP's affinity for ChoP-glycans. However, there appear to have been no direct measurements of CRP's binding constants for ChoP glycans or fragments thereof. The reactivity of CRP with $H$. influenzae LPS varies with the location of the ChoP in the antigen, which leads to different sensitivities of the Eagan and Rd strains to CRP-related serum killing (Lysenko et al., 2000). Similarly, the precipitation curves for CRP with PnC and the type 27 S. pneumoniae polysaccharide were quite different (Young and Williams, 1978). Hence CRP's interactions with ChoP groups on glycans are context dependent.

\subsection{Toll-like receptors}

A family of pattern recognition molecules, Toll-like receptors (TLRs) are components of innate immunity that respond to conserved features of pathogens (for an overview, see Kawai and Akira, 2010). TLR4 recognizes diverse LPS species, primarily through the phosphorylated GlcNAc residues of the common lipid A component (Park et al., 2009). While ChoP groups on lipopolysaccharides do not affect TLR4 recognition, ChoP groups on the glycoprotein ES-62 from the parasite Ascaris vitaea can mediate binding to TLR4, resulting in a reduction in mast cell degranulation. The ChoP groups of ES-62 also exert a variety of other immunomodulatory effects through their interactions with T-and B-cell receptors, summarized in Grabitzki and Lochnit (2009).

A second TLR, TLR2 has been reported to interact with S. pneumoniae and Staphylococcus aureus LTAs (Schroder et al., 2003), but this receptor is now thought to be specific for lipoproteins (Zahringer et al., 2008). In the case of S. pneumoniae ChoP-LTA, investigations with TLR2-/- mice showed no role for the ChoP groups (Gehre et al., 2009). Similarly, Pang et al. (2008) showed that TLR2 did not affect the clearance of non-typeable $H$. influenzae bearing ChoP-LPS.

\section{4. $\mathrm{MHCII}$}

MHC class II molecules present peptides derived from extracellular proteins that have been endocytosed and digested in lysosomes, to T-cell receptors. In addition to this "classic" function, a totally different type of MHCII interaction with polysaccharides was discovered by Kasper and co-workers. They have shown that polysaccharides that carry both negative and positively charged groups, i.e., that are zwitterionic, can interact directly with MHCII molecules (Choi et al., 2002; Cobb and Kasper, 2008). The group of such ZPSs identified so far includes S. pneumoniae PnC (Tzianabos et al., 1993), a phosphoethanolamine-bearing polysaccharide from Bacteroides fragilis, polysaccharide B (Tzianabos et al., 1995), and the $O$-chain of M. morganii (Young et al., 2011). Whether the zwitterionic character of ChoP or phosphoethanolamine alone is sufficient to confer ZPS-MHCII reactivity on a polysaccharide is not known, as all these polysaccharides carry other charged groups. The type $32 \mathrm{~S}$. pneumoniae polysaccharides and the $P$. mirabilis O18 O-chain have ChoP as their only charged groups (Table 1) so it would be interesting to see if they can interact with MHCII molecules. There does not have to be an equal number of -ve and +ve charged groups on the ZPS, since acetylation of the amino group of the M. morganii $O$-chain did not affect its interaction with MHCII molecules (Young et al., 2011). A minimum size of $\sim 10 \mathrm{kDa}$ is necessary, and oligomeric fragments did not inhibit the binding of ZPS in the manner of a hapten. On the basis of the most investigated ZPSs, polysaccharide A (PSA) from B. fragilis and S. pneumoniae type 1 polysaccharide, it was proposed that folding of the ZPS into a helical form was required for its interaction with MHCII (Choi et al., 2002; Kreisman et al., 2007), but the M. morganii O-chain did not show any helicity (Young et al., 2011). There are no structural data on how any ZPS is bound by MHCII molecules, but the binding is primarily electrostatic since it is inhibited by addition of salt (Cobb and Kasper, 2008). In HLA-DR1, the MHCII species used for in vitro assays with ZPS, the peptide-binding cleft has only four widely spaced charged residues (Stern et al., 1994; PDB code 1DLH). But there are two patches of negatively and positively charged residues elsewhere on its surface, chiefly consisting of Glu and Arg residues (Fig. 4).

\subsection{Antibodies and myeloma proteins}

Tests of mouse myeloma proteins from plasmacytomas induced with mineral oil disclosed a group of six such proteins that recognized PnC through its ChoP groups (Leon and Young, 1971). As more of them were found, they were classified into three groups named M603, M511 and T15 from properties of their prototypes, including their idiotypes. They share a common $\mathrm{VH}$ gene but use different $V L$ genes. The M603 Fab was the first antibody fragment whose complex with a hapten (ChoP) was solved by X-ray crystallography (Satow et al., 1986; PDB code 2MCP), and it confirmed that antibody binding sites were centrally located on the Fv and were formed from the six CDRs (Fig. 4). In an attempt to discover what might have been the initial antigen that had triggered the lymphocytes from which the myelomas were formed by the mineral oil, Potter (1971) tested a variety of organisms from the mouse 


\section{CRP}

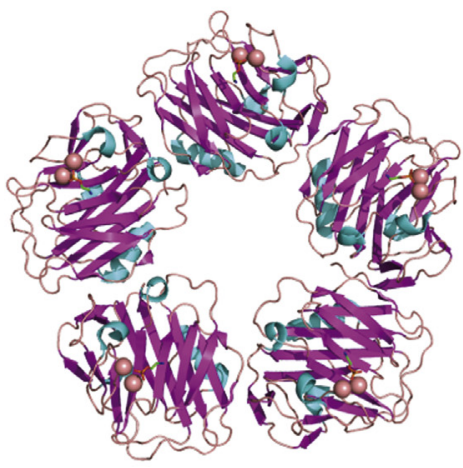

$\mathrm{MHCll}$

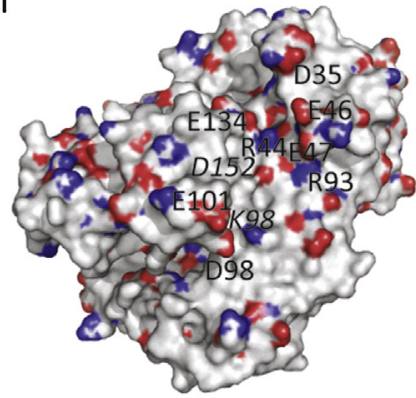

$\mathrm{M} 603$

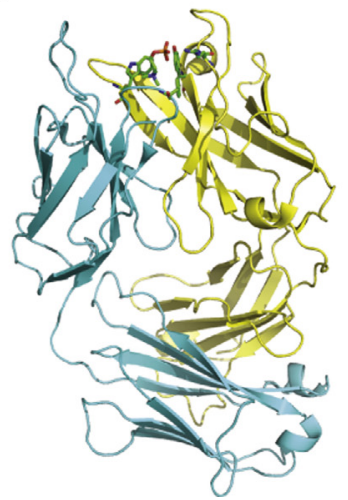

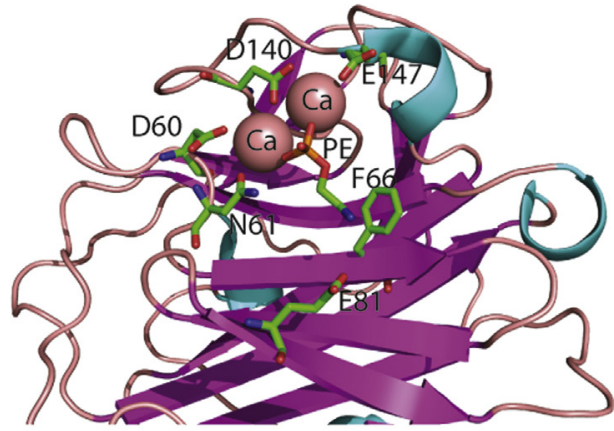

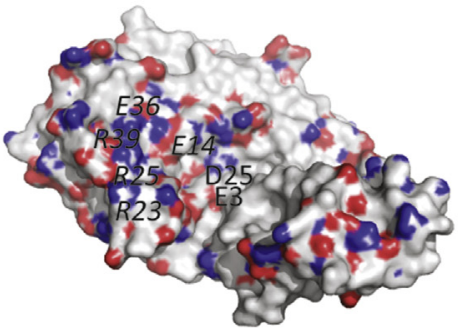

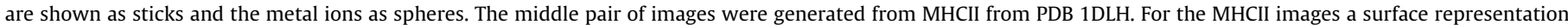

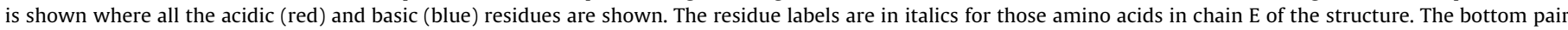

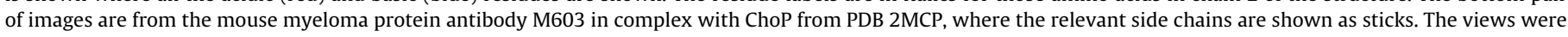
created with the PyMOL Molecular Graphics System, Version 1.5.0.4 Schrödinger, LLC.

cage environment and discovered that two of the organisms mentioned above, M. morganii and A. suum, carried ChoP-glycans, as did Aspergillus niger. The structure of the antigen from the latter has not been described, but other fungi are known to have ChoP groups on their galactomannans, e.g., Penicillium charlesii (Unkefer et al., 1982) where ChoP occurs on the 06 of the mannose residues.

ChoP groups on glycans are immunodominant epitopes. Therefore phosphocholine is usually a potent hapten for their antibodies, and mouse hybridoma antibodies raised against ChoP-glycans fall into the same three families as the myeloma proteins (Claflin et al., 1981). Antibodies from the different families vary in their protection of mice against $S$. pneumoniae with T15 being the most effective, and the antibody response to PnC is mainly composed of T15-like antibodies (Claflin and Berry, 1988). In contrast, antibodies to $M$. morganii are predominantly of the M603 class, and antibodies to A. suum were in the M511 class (Claflin et al., 1985). Though the T15 myeloma protein is very often used as a reagent to detect ChoP on glycans, it does not recognize all ChoP antigens; for example, it does not react with the $M$. morganii $O$-chain, probably because the ChoP is in a more crowded environment. The immunogenetics of mouse antibodies to the $M$. morganii ChoP-glycan and their clonal nature were extensively investigated by Claflin and coworkers (Claflin et al., 1987, 1989).

Normal sera from both mice and humans carry anti-ChoP antibodies. The human response is mainly IgG2 and it is also restricted in its V-gene usage (Scott et al., 1987). The levels of ChoP antibodies vary with age, and the level has been suggested as a marker for the ability of a patient to respond to carbohydrate antigens generally (Briles et al., 1987). Anti-ChoP antibodies purified from pooled human plasma were capable of killing S. pneumoniae and $H$. influenzae in vitro, and were protective against a virulent $S$. pneumoniae strain in a mouse passive transfer assay (Goldenberg et al., 2004). Furthermore, natural and passive antibodies in mice enhanced the clearance of $S$. pneumoniae from blood (McDaniel et al., 1984). Since ChoP is present on several 
pathogenic bacteria, raising the levels of anti-ChoP antibodies by immunization with conjugates such as ChoP-keyhole limpet hemocyanin has been investigated as a means of producing a wide-ranging immunity. Serum antibodies elicited in this way were mainly IgG3 and IgM, and conferred resistance to challenge with S. pneumoniae (Wallick et al., 1983). Because this protection could be expected to extend to other intranasal ChoP-bearing pathogens such as $H$. influenzae, there has been on-going interest in ChoP-protein conjugates as vaccines. For example, in an intranasal infection model in mice, the same conjugate antigen induced salivary IgA antibodies which enhanced clearance of both $S$. pneumoniae and $H$. influenzae from the nasal tract (Tanaka et al., 2007). However, in many circumstances the PnC and its ChoP epitopes may be concealed by the outer layer of capsular polysaccharide.

An interesting side-property of human anti-ChoP antibodies is their protective role against cardiovascular disease, which may arise through the presence of ChoP on oxidized low-density lipoproteins. In mice, autoantibodies of the T15 class specifically bound to oxidized phospholipids and to apoptotic cells (Shaw et al., 2000), and competed with CRP for them (Chang et al., 2002). Low levels of human anti-ChoP antibodies have been proposed as a risk marker for atherosclerosis (Frostegård, 2010), and in animal models, active immunization with ChoP and passive immunization with anti-ChoP antibodies both ameliorated cardiovascular disease (de Faire and Frostegård, 2009). It is somewhat ironic that exposure to pathogens bearing ChoP glycans may therefore have a beneficial effect.

\section{Conclusions}

Taken overall, there are several features of ChoP glycans that are striking.

(1) Though the known examples are relatively few, they are distributed throughout the classes of bacterial glycans. Furthermore, the ChoP groups are attached at very different sites, both in the hexoses that are substituted and the hydroxyl positions that receive the ChoP groups. This characteristic is in accord with the sequence diversity of the LicD enzymes that are responsible for ChoP attachment.

(2) The widespread presence of host proteins capable of reacting with ChoP glycans, notably CRP and antibodies, means that there are considerable immune defensives, both innate and adaptive, primed to act against organisms that carry ChoP glycans. The wide distribution of CRP in animal species shows this capacity is not restricted to humans and mice. For a pathogen to evolve to make ChoP glycans therefore requires that the potential for uptake by the PAF receptor must outweigh these disadvantages. For the nasopharyngeal pathogens such as $H$. influenzae, S. pneumoniae and Neisseria species, this trade-off is evidently worthwhile, though they have also evolved ways to moderate the risk, e.g., phase variation of ChoP expression in $H$. influenzae. What role binding to the PAF receptor may play in the process of infection by other bacteria such as $C$. upsaliensis, $P$. mirabilis and $M$. morganii remains to be determined, however.

(3) This balance of factors makes the presence of licD genes in other bacteria whose genomes are now available very striking. Apparently other pathogenic bacteria can express ChoP glycans, though they would have to synthesize or acquire choline to do so, and have ways to balance the exploitation of the PAF receptor against susceptibility to $C R P$ and the adaptive immune system.

\section{Disclosure}

No competing financial interests exist.

\section{Acknowledgments}

We thank David Watson for assistance with bioinformatics, and Dr. Elke Schweda and Dr. Jim Richards for their valuable comments on the manuscript. We thank Lisa Willis for help with the Pymol figures.

\section{References}

Abernathy, T.J., Avery, O.T., 1941. The occurrence during acute infections of a protein not normally present in the blood. I. Distribution of the reactive protein in patients sera and the effect of calcium on the flocculation reaction with $\mathrm{C}$ polysaccharide of pneumococcus. Journal of Experimental Medicine 73, 173-182.

Bach, B.A., Gewurz, H., Osmand, A.P., 1977. C-reactive protein in the rabbit: isolation, characterization and binding affinity to phosphocholine. Immunochemistry 14 215-219.

Bennett, L.G., Bishop, C.T., 1977. Structure of the type XXVII Streptococcus pneumoniae (pneumococcal) capsular polysaccharide. Canadian Journal of Chemistry $55,8-16$.

Bentley, S.D., Aanensen, D.M., Mavroidi, A., Saunders, D., Rabbinowitsch, E., Collins, M., Donohoe, K., Harris, D., Murphy, L., Quail, M.A., Samuel, G., Skovsted, I.C., Kaltoft, M.S., Barrell, B., Reeves, P.R., Parkhill, J., Spratt, B.G., 2006. Genetic analysis of the capsular biosynthetic locus from all 90 pneumococcal serotypes. PLoS Genetics 2, E31.

Black, S., Kushner, I., Samois, D., 2004. C-reactive protein. Journal of Biological Chemistry 279, 48487-48490.

Briles, D.E., Scott, G., Gray, B., Crain, M.J., Blaese, M., Nahm, M., Scott, V., Haber, P., 1987. Naturally occurring antibodies to phosphocholine as a potential index of antibody responsiveness to polysaccharides. Journal of Infectious Diseases 155 1307-1314

Chang, M.-K., Binder, C.J., Torzewski, M., Witztum, J.L., 2002. C-reactive protein binds to both oxidized LDL and apoptotic cells through recognition of a common ligand: phosphorylcholine of oxidized phospholipids. Proceedings of the National Academy of Sciences of the United States of America 99, 13043-13048.

Choi, Y.H., Roehrl, M.H., Kasper, D.L., Wang, J.Y., 2002. A unique structural pattern shared by T-cell-activating and abscess-regulating zwitterionic polysaccharides. Biochemistry 41, 15144-15151.

Claflin, J.L., Berry, J., 1988. Genetics of the phosphocholine-specific antibody response to Streptococcus pneumoniae Germ-line but not mutated T15 antibodies are dominantly selected. Journal of Immunology 141, 4012-4019.

Claflin, J.L., Berry, J., Flaherty, D., Dunnick, W., 1987. Somatic evolution of diversity among anti-phosphocholine antibodies induced with Proteus morganii. Journal of Immunology 136, 3060-3068.

Claflin, J.L., Hudak, S., Maddelena, A., 1981. Anti-phosphocholine hybridoma antibodies. 1. Direct evidence for three distinct families of antibodies in the murine response. Journal of Experimental Medicine 153, 352-364.

Claflin, J.L., Hudak, S., Maddalena, A., Bender, T., 1985. Antigen-specific antiphosphocholine antibodies: binding site studies. Journal of Immunology 134, 2536-2543.

Claflin, J.L., George, J., Dell, C., Berry, J., 1989. Patterns of mutations and selection in antibodies to the phosphocholine-specific determinant in Proteus morganii. Journal of Immunology 143, 3054-3063.

Clark, S.E., Weiser, J.N., 2013. Microbial modulation of host immunity with the small molecule phosphorylcholine. Infection and Immunity 81, 392-401.

Cobb, B.A., Kasper, D.L., 2008. Characteristics of carbohydrate antigen binding to the presentation protein HLA-DR. Glycobiology 18, 707-718.

Cox, A.D., Howard, M.D., Brisson, J.-R., van der Zwan, M., thibault, P., Perry, M.B., Inzana, T.J., 1998. Structural analysis of the phase-variable lipooligosaccharide from Haemophilus somnus strain 738. European Journal of Biochemistry 253, 507-516.

Cundell, D.R., Gerard, N.P., Gerard, C., Idanpaan-Heikkila, I., Tuomanen, E.I., 1995. Streptococcus pneumoniae anchor to activated human cells by the receptor for platelet-activating factor. Nature 377, 435-438.

Cundell, D.R., Gerard, C., Idanpaan-Heikkila, I., Tuomanen, E.I., Gerard, N.P., 1996. PAF receptor anchors Streptococcus pneumoniae to activated human epithelial cells. Advances in Experimental Medicine and Biology 416, 89-94.

Denapaite, D., Brückner, R., Hakenbeck, R., Vollmer, W., 2012. Biosynthesis of teichoic acids in Streptococcus pneumoniae and closely related species: lessons from genomes. Microbial Drug Resistance 18, 344-358.

Draing, C., Pfitzenmaier, M., Zummo, S., Mancuso, G., Geyer, A., Hartung, T., von Aulock, S., 2006. Comparison of lipoteichoic acid from different serotypes of Streptococcus pneumoniae. Journal of Biological Chemistry 281, 33849-33859.

Elswaifi, S.F., St Michael, F., Sreenivas, A., Cox, A., Carman, G.M., Inzana, T., 2009. Molecular characterization of phosphorylcholine expression on the lipooligosaccharide of Histophilus somnus. Microbial Pathogenesis 47, 223-230.

de Faire, U., Frostegård, J., 2009. Natural antibodies against phosphorylcholine in cardiovascular disease. Annals of the New York Academy of Sciences 1173, 292-300. 
Fan, X., Goldfine, H., Lysenko, E., Weiser, J.N., 2001. The transfer of choline from the host to the bacterial cell surface requires glpQ in Haemophilus influenzae. Molecular Microbiology 41, 1029-1036.

Fischer, W., Behr, T., Hartmann, R., Peter-Katalinć, J., Egge, H., 1993. Teichoic acid and lipoteichoic acid of Streptococcus pneumoniae possess identical chain structures: a reinvestigation of teichoic acid (C polysaccharide). European Journal of Biochemistry 215, 851-857.

Forsgren, A., Riesbeck, K., Janson, H., 2008. Protein D of Haemophilus influenzae: a protective nontypeable $H$ influenzae antigen and a carrier for pneumococcal conjugate vaccines. Clinical Infectious Diseases 46, 726-731.

Fouts, D.E., Mongodin, E.F., Mandrell, R.E., Miller, W.G., Rasko, D.A., et al., 2005. Major structural differences and novel potential virulence mechanisms from the genomes of multiple Campylobacter species. PLoS Biology 3, e15

Fox, K.L., Schweda, E.K., Vitiazeva, V., Makepiece, K., Jennings, M.P., Moxon, E.R., Hood, D.W., 2008. Dulicate copies of lic1 direct the addition of multiple phosphocholine residues in the lipopolysaccharide of Haemophilus influenzae. Infection and Immunity 76, 588-600.

Frostegård, J., 2010. Low level natural antibodies against phosphorylcholine: a novel risk marker and potential mechanism in atherosclerosis and cardiovascular disease. Clinical Immunology 134, 47-54.

Fudala, R., Kondakova, A.N., Bednarska, K., Senchenkova, S.N., Shashkov, A.S., Knirel, Y.A., Zahringer, U., Kaca, W., 2003. Structure and serological characterization of the O-antigen of Proteus mirabilis 018 with a phosphocholine-containing oligosaccharide repeating unit. Carbohydrate Research 338, 1835-1842.

Gang, T.B., Hammond, D.J., Singh, S.K., Ferguson, D.A., Mishra, V.K., Agrawal, A., 2013. The phosphorylcholine-binding pocket on C-reactive protein is necessary for initial protection of mice against pneumococcal infection. Journal of Biological Chemistry 287, 43116-43125.

Garau, G., Lemaire, D., Vernet, T., Dideberg, O., Di Guilmi, A.M., 2005. Crystal structure of phosphocholine esterase domain of the virulence factor choline-binding protein E from Streptococcus pneumoniae. Journal of Biological Chemistry 280, 28591-28600.

Gehre, F., Spisek, R., Kharat, A.S., Matthews, P., Kukreja, A., Anthony, R.M., Dhodapkar, M.V., Vollmer, W., Tomasz, A., 2009. Role of teichoic acid choline moieties in the virulence of Streptococcus pneumoniae. Infection and Immunity 77, 2824-2831.

Goldenberg, H.B., McCool, T.L., Weiser, J.N., 2004. Cross-reactivity of human immunoglobulin G2 recognizing phosphorylcholine and evidence for protection against major bacterial pathogens of the human respiratory tract. Journal of Infectious Diseases 190, 1254-1263.

Grabitzki, J., Lochnit, G., 2009. Immunomodulation by phosphocholine - biosynthesis structures and immunological implications of parasitic PC-epitopes. Molecular Immunology 47, 149-163.

Hong, W., Mason, K., Jurcisek, J., Novotny, L., Bakaletz, L.O., Swords, W.E., 2007a. Phosphorylcholine decreases early inflammation and promotes the estatblishment of stable biofilm communities of nontypeable Haemophilus influenzae strain 86-028NP in a chinchilla model of otitis media. Infection and Immunity 75, 958-965.

Hong, W., Pang, B., West-Barnette, S., Swords, W.E., 2007b. Phosphorylcholien expression by nontypeable Haemophilus influenzae correlates with maturation of biofilm communities in vitro and in vivo. Journal of Bacteriology 189, 8300-8307.

Hermoso, J.A., Lagartera, L., González, A., Stelter, M., García, P., Martínez-Ripoll, M., García, J.L., Menéndez, M., 2005. Insights into pneumococcal pathogenesis from the crystal structure of the modular teichoic acid phosphorylcholine esterase Pce. Nature Structural \& Molecular Biology 12, 533-538.

Howard, M.D., Cox, A.D., Weiser, J.N., Schurig, G.G., Inzana, T.J., 2000. Antigenic diversity of Haemophilus somnus lipooligosaccharide: phase-variable accessibility of the phosphorylcholine epitope. Journal of Clinical Microbiology 38, 4412-4419.

Jansson, P.-E., Lindberg, B., Lindquist, U., Ljungberg, J., 1987. Structural studies of the capsular polysaccharide from Streptococcus pneumoniae types 15B and 15C. Carbohydrate Research 162, 111-116.

Kajihara, A., Komooka, H., Kamiya, K., Yoneda, T., Yoneda, S., Nakamura, M., Shimizu, T., Umeyama, H., 1994. Three-dimensional model of the human PAF receptor. Journal of Lipid Mediators and Cell Signalling 9, 185-196.

Karlsson, C., Jansson, P.-E., Sørenson, U.B., 1998. The chemical structures of the capsular polysaccharides from Streptococcus pneumoniae types $32 \mathrm{~F}$ and $32 \mathrm{~A}$. European Journal of Biochemistry 255, 296-302.

Karlsson, C., Jansson, P.-E., Skov Sorenson, U.B., 1999. The pneumococcal common antigen C-polysaccharide occurs in different forms; mono-substituted or di-substituted with phosphocholine. European Journal of Biochemistry 265, 1091-1097.

Kawai, T., Akira, S., 2010. The role of pattern-recognition receptors in innate immunity: update on Toll-like receptors. Nature Immunology 11, 373-384.

Kreisman, L.S.C., Friedman, J.H., Neaga, A., Cobb, B.A., 2007. Structure and function relations with a T-cell-activating polysaccharide antigen using circular dichroism. Glycobiology 17, 46-55.

Kulakowska, M., Brisson, J.-R., Griffith, D.W., Young, N.M., Jennings, H.J., 1993. Highresolution NMR spectroscopic analysis of the C-polysaccharide of Streptococcus pneumoniae. Canadian Journal of Chemistry 71, 644-648.

Kwak, B.-Y., Zhang, Y.-M., Yun, M., Heath, R.J., Rock, C.O., Jackowski, S., Park, H.-W., 2002. Structure and mechanism of CTP:phosphocholine cytidyltransferase (LicC) from Streptococcus pneumoniae. Journal of Biological Chemistry 277 ,4343-4350.

Larkin, A., Imperiali, B., 2011. The expanding horizons of asparagine-linked glycosylation. Biochemistry 50, 4411-4428.

Leon, M.A., Young, N.M., 1971. Specificity for phosphorylcholine of six murine myeloma proteins reactive with Pneumococcus $C$ polysaccharide and $\beta$ lipoproteins. Biochemistry 10, 1424-1429.
Lochnit, G., Dennis, R.D., Ulmer, A.J., Geyer, R., 1998. Structural elucidation and monokine-inducing activity of two biologically active zwitterionic glycosphingolipids derived from the porcine parasitic nematode Ascaris suum. Journal of Biological Chemistry 273, 466-474.

Lundström, S.L., Li, J., Deadman, M.E., Hood, D.W., Moxon, E.R., Schweda, E.K.H., 2008 Structural analysis of the lipopolysaccharide from nontypeable Haemophilus influenzae strain R2846. Biochemistry 47, 6025-6038.

Lysenko, E., Richards, J.C., Cox, A.D., Stewart, A., Martin, A., Kapoor, M., Weiser J.N., 2000. The position of phosphorylcholine on the lipopolysaccharide of Haemophilus influenzae affects binding and sensitivity to C-reactive proteinmediated killing. Molecular Microbiology 35, 234-245.

MacLeod, C.M., Avery, O.T., 1941a. The occurrence during acute infections of a protein not normally present in the blood. II. Isolation and properties of the reactive protein. Journal of Experimental Medicine 73, 183-190.

MacLeod, C.M., Avery, O.T., 1941b. The occurrence during acute infections of a protein not normally present in the blood III. Immunological properties of the C-reactive protein and its differentiation from normal blood proteins. Journa of Experimental Medicine 73, 190-200.

Månsson, M., Bauer, S.H., Hood, D.W., Richards, J.C., Moxon, E.R., Schweda, E.K., 2001 A new structural type for Haemophilus influenzae lipopolysaccharide Structura analysis of the lipopolysaccharide from nontypeable Haemophilus influenzae strain 486. European Journal of Biochemistry 268, 2148-2159.

Mao, F., Dam, P., Chou, J., Olman, V., Xu, Y., 2009. DOOR: a database for prokaryotic operons. Nucleic Acids Research 37, D459-D463.

McDaniel, L.S., Benjamin Jr., W.H., Forman, C., Briles, D.E., 1984. Blood clearance by anti-phosphocholine antibodies as a mechanism of protection in experimental pneumococcal bacteremia. Journal of Immunology 133, 3308-3312.

Mikolajek, H., Kolstoe, S.E., Pye, V.E., Mangione, P., Pepys, M.B., Wood, S.P., 2010 Structural basis of ligand specificity in the human pentraxins, C-reactive protein and serum amyloid P component. Journal of Molecular Recognition 24, 371-377.

Munson, R.S., Sasaki, K., 1993. Protein D, a putative immunoglobulin D-binding protein produced by Haemophilus influenzae, is a glycerophosphodiester phosphodiesterase. Journal of Bacteriology 175, 4569-4571.

Naessan, C.L., Egge-Jacobsen, W., Heiniger, R.W., Wolfgang, M.C., Aas, F.E., Røhr A., Winther-Larsen, H.C., Koomey, M., 2008. Genetic and functional analysis of PptA a phospho-form transferase targettig type IBV pili in Neisseria gonorhoeae. Journal of Bacteriology 190, 387-400.

Pang, B., Winn, D., Johnson, R., Hong, W., West-Barnette, S., Kock, N., Swords W.E., 2008. Lipopolysaccharides containing phosphorylcholine delay pulmonary clearance of non-typeable Haemophilus influenzae. Infection and Immunity 76, 2037-2043

Park, B.S., Song, D.H., Kim, H.M., Choi, B.-S., Lee, H., Lee, J.-O., 2009. The structura basis of lipopolysaccharide recognition by the TLR4-MD-2 complex. Nature 458 1191-1196.

Potter, M., 1971. Antigen-binding myeloma proteins in mice. Annals of the New York Academy of Sciences 190, 306-321.

Risberg, A., Masoud, H., Martin, A., Richards, J.C., Moxon, E.R., Schweda, E.K.H., 1999 Structural analysis of the lipopolysaccharide epitopes expressed by a capsuledeficient strain of Haemophilus influenzae Rd. European Journal of Biochemistry $261,171-180$.

Robey, F.A., Liu, T.Y., 1981. Limulin, a C-reactive protein from Limulus polyphemus Journal of Biological Chemistry 256, 969-975

Satow, Y, Cohen, G.H. Padlan, E.A., Davies, D.R., 1986. Phosphocholine binding immunoglobulin Fab McPC603. An X-ray diffraction study at $2.7 \AA$. Journal of Molecular Biology 190, 593-603.

Schroder, N.W.J., Morath, S., Alexander, C., Hamann, L., Hartung, T., Zahringer, U., Gobel, U.B., Weber, J.R., Schumann, R.R., 2003. Lipoteichoic acid (LTA) of Streptococcus pneumoniae and Staphylococcus aureus activates immune cells via Toll-like receptor (TLR)-2, lipopolysaccharide binding protein (LBP) and CD14, whereas TLR-4 and MD-2 are not involved. Journal of Biological Chemistry 278 $15587-15594$.

Schweda, E.K.H., Brisson, J.-R., Alvelius, G., Martin, A., Weiser, J.N., Hood, D.W. Moxon, E.R., Richards, J.C., 2000. Characterization of the phosphocholinesubstituted oligosaccharides in lipopolysaccharides of type b Haemophilus influenzae. European Journal of Biochemistry 267, 3902-3913.

Schweda, E.K.H., Richards, J.C., Hood, D.W., Moxon, E.R., 2007. Expression and structural diversity of the lipopolysaccharide of Haemophilus influenzae: implication in virulence. International Journal of Medical Microbiology 297, 297-306

Scott, M.G., Briles, D.E., Shackelford, P.G., Smith, D.S., Nahm, M.H., 1987. Human antibodies to phosphocholine IgG anti-PC antibodies express restricted numbers of $\mathrm{V}$ and $\mathrm{C}$ regions. Journal of Immunology 138, 3325-3331.

Seo, H.S., Cartee, R.T., Pritchard, D.G., Nahm, M.H., 2008. A new model of pneumococcal lipoteichoic acid structure resolves biochemical, biosynthetic, and serological inconsistencies of the current model. Journal of Bacteriology 190 2379-2387

Serino, L., Virij, M., 2000. Phosphorylcholine decoration of lipopolysaccharide differentiates commensal Neisseria from pathogenic strains Identification of licA-type genes in commensal Neisseria. Molecular Microbiology 35, 1550-1559.

Serino, L., Virij, M., 2002. Genetic and functional analysis of the phosphorylcholine moiety of commensal Neisseria lipopolysaccharide. Molecular Microbiology 43 437-448.

Shaw, P.X., Hörkkö, S., Chang, M.-K., Curtiss, L.K., Palinski, W., Silverman, G.J. Witztum, J.L., 2000. Natural antibodies with the T15 idiotype may act in atherosclerosis, apoptotic clearance, and protective immunity. Journal of Clinical Investigation 105, 1731-1740. 
Shrive, A.K., Cheetham, G.M.T., Holden, D., Myles, D.A.A., Turnell, W.G., Volanakis, J.E., Pepys, M.B., Bloomer, A.C., Greenhough, T.J., 1996. Three dimensional structure of human C-reactive protein. Nature Structural \& Molecular Biology 3, 346-354.

Skov Sørensen, U.B., Agger, R., Bennedsen, J., Henrichsen, J., 1984. Phosphorylcholine determinants in six pneumococcal capsular polysaccharides detected by monoclonal antibody. Infection and Immunity 43, 876-878.

Smani, Y., Docobo-Pérez, F., López-Rojas, R., Domínguez-Herrera, J., IbánezMartínez, J., Pachón, J., 2012. Platelet-activating factor receptor initiates contact of Acinetobacter baumannii expressing phosphorylcholine with host cells. Journal of Biological Chemistry 287, 26901-26910.

Stern, L.J., Brown, J.H., Jardetzky, T.S., Gorga, J.C., Urban, R.G., Strominger, J.L., Wiley, D.C., 1994. Crystal structure of the human class II MHC protein HLA-DR1 complexed with an influenza virus peptide. Nature 368, 215-221.

St. Michael, F., Li, J., Vinogradov, E., Larocque, S., Harper, M., Cox, A.D., 2005a. Structural analysis of the lipopolysaccharide from Pasteurella multocida strain VP161: identification of both Kdo-P and Kdo-Kdo species in the lipopolysaccharide. Carbohydrate Research 340, 59-68.

St. Michael, F., Li, J., Cox, A.D., 2005b. Structural analysis of the core oligosaccharide from Pasteurella multocida strain X73. Carbohydrate Research 340, 1253-1257.

Swords, A.P., Buscher, B.A., Ver Steeg li, K., Preston, A., Nichols, W.A., Weiser, J.N., Gibson, B.W., Apicella, M.A., 2000. Non-typeable Haemophilus influenzae adhere to and invade human bronchial epithelial cells via an interaction of lipooligosaccharide with the PAF receptor. Molecular Microbiology 37, 13-27.

Swords, W.E., Jones, P.A., Apicella, M.A., 2003. The lipo-oligosaccharides of Haemophilus influenzae: an interesting array of characters. Journal of Endotoxin Research 9, 131-144

Szalai, A.J., Briles, D.E., Volanakis, J.E., 1995. Human C-reactive protein is protective against fatal Streptococcus pneumoniae infection in transgenic mice. Journal of Immunology 155, 2557-2563.

Tan, Y., Arnold, R.J., Luo, Z.-Q., 2011. Legionella pneumophila regulates the small GTPase Rab1 activity by reversible phosphorylcholination. Proceedings of the National Academy of Sciences of the United States of America 108, 21212-21217.

Tanaka, N., Fukuyama, T.N., Fukuiwa, T., Kawabata, M., Sagara, Y., Ito, H.O., Miwa, Y., Nagatake, T., Kiyono, H., Kurono, Y., 2007. Intranasal immunization with phosphorylcholine induces antigen specific mucosal and systemic immune responses in mice. Vaccine 30, 2680-2687.

Tillett, W.S., Francis, T., 1930. Serological reactions in pneumonia with a nonprotein somatic fraction of pneumococcus. Journal of Experimental Medicine 52, $561-571$.

Tzianabos, A.O., Onderdonk, A.B., Rosner, B., Cisneros, R.L., Kasper, D.L., 1993. Structural features of polysaccharides that induce intra-abdominal abscesses. Science 262, 416-419.

Tzianabos, A.O., Kasper, D.L., Onderdonk, A.B., 1995. Structure and function of Bacteroides fragilis capsular polysaccharides: relationship to induction and prevention of abscesses. Clinical Infectious Diseases 2 (20 Suppl.), S132-S140.
Unkefer, C.J., Jackson, C., Gander, J.E., 1982. The 5-O- $\beta$-D-galactofuranosylcontaining glycopeptide from Penicillium charlesii. Journal of Biological Chemistry 257, 2491-2497.

Vitazeva, V., Li, J., Hood, D.W., Moxon, E.R., Schweda, E.K.H., 2012. The structural diversity of lipopolysaccahride expressed by non-typeable Haemophilus influenzae strains 1158 and 1159. Carbohydrate Research 357, 98-110.

Volanakis, J.E., Kaplan, M.H., 1971. Specificity of C-reactive protein for choline phosphate residues of pneumococcal C-polysaccharide. Proceedings of the Society for Experimental Biology and Medicine 136, 612-614.

Vollmer, W., Tomasz, A., 2001. Identification of the teichoic acid phosphorylcholine esterase in Streptococcus pneumoniae. Molecular Microbiology 39, 1610-1622.

Wallick, S., Claflin, J.L., Briles, D.E., 1983. Resistance to Streptococcus pneumoniae is induced by a phosphocholine-protein conjugate. Journal of Immunology 130, 2871-2875.

Weiser, J.N., Goldberg, J.B., Pan, N., Wilson, L., Viriji, M., 1998. The phosphorylcholine epitope undergoes phase variation on a 43-kilodalton protein in Pseudomonas aeruginosa and on pili of Neisseria meningitidis and Neisseria gonorrhoeae. Infection and Immunity 66, 4263-4267.

Weiser, J.N., Pan, N., McGowan, K.L., Musher, D., Martin, A., Richards, J., 2007. Phosphorylcholine on the lipopolysaccharide of Haemophilus influenzae contributes to persistance in the respiratory tract and sensitivity to serum killing mediated by C-reactive protein. Journal of Experimental Medicine 187, 631-640.

Weiser, J.N., Shchepetov, M., Chong, S.T.H., 1997. Decoration of lipopolysaccharide with phosphorylcholine: a phase-variable characteristic of Haemophilus influenzae. Infection and Immunity 65, 943-950.

Yildirim, H.H., Li, J., Richards, J.C., Hood, D.W., Moxon, E.R., Schweda, E.K.H., 2005 An alternate pattern for globoside oligosaccharide expression in Haemophilus influenzae lipopolysaccharide: structural diversity in nontypeable strain 1124 Biochemistry 44, 5207-5224.

Yost, C.C., Weyrich, A.S., Zimmerman, G.A., 2010. The platelet activating factor (PAF) signalling cascade in systemic inflammatory responses. Biochimie 92, 692-697.

Young, N.M., Kreisman, L.S.C., Stupak, J., MacLean, L.L., Cobb, B.A., Richards, J.C., 2011. Structural characterization and MHCII-dependent immunological properties of the zwitterionic O-chain antigen of Morganella morganii. Glycobiology $21,1266-1276$

Young, N.M., Williams, R.E., 1978. Comparison of the secondary structures and binding sites of C-reactive protein and the phosphorylcholine-binding murine myeloma proteins. Journal of Immunology 121, 1893-1898.

Zahringer, U., Lindner, B., Inamura, S., Heine, H., Alexander, C., 2008. TLR2 - promiscuous or specific? A critical re-evaluation of a receptor expressing apparent broad specificity. Immunobiology 213, 205-224.

Zhang, J.-R., Idanpaan-Heikkila, I., Fisher, W., Tuomanen, E.I., 1999. Pneumococcal licD2 gene is involved in phosphorylcholine metabolism. Molecular Microbiology $31,1477-1488$. 